\title{
Introduction \\ Transcending Structure-Agency in the Study of Organizations
}

\section{Vita Peacock and Philip Kao}

What is the relation between our own daily activity and the organizations that almost all of us are members of? This seemingly simple question has dominated the social study of organizations for over a century, and the responses to it can be very broadly parcelled out into three alternative perspectives. The first argues that this organization, (whether a school, a university, a corporation, a union, or any other substantial social group) has a determinate relationship to our activity within it, being larger and more powerful than we are as individuals. The second maintains that through our activity and exchange with other individuals within them, we in fact co-constitute such groups. The third perspective seeks to get around the predominance of one over the other, by asserting that both elements of this relationship are in dialectical synthesis. Welcome to the Möbius strip of the so-called 'structure-agency problem', which continues to drive organizational theorists in dizzying circles. Emerging from a workshop hosted by the Department of Anthropology at University College London in July 2012, we ask in this Special Issue: has the 'structure-agency problem' itself become a problem? Is the time for 'rethinking' this binary finally past (Reed 1997)? Is now the moment to snip the strip to see in which directions its severed ends might lead us?

Before reaching for the scissors, a brief and schematic synopsis of the problem - as defined by its most influential intermediaries - will be necessary. ${ }^{1}$ The story begins with the divergent perspectives of two foundational figures in the study of organizations: Émile Durkheim and Max Weber. For Durkheim, an analysis of social structure was the key to understanding individual behaviour. The family, the law, religion, and economic and political life constituted such 'structures', enforcing their collective will through 'social facts' (Durkheim 1982: 50), which produced the social being of their members. These structures and their material expressions produced the relationship of human beings to one other: their 'solidarity' (Durkheim 1997). One's relative 'integration' into, and 'regulation' by, these structures could even determine different forms of suicide, previously conceived to be the most unambiguous case of individual choice (Durkheim 1952). For Durkheim, the 'thoughts to be found in the consciousness of individuals' were irrelevant (1982: 54). When individuals became part of social groups they were helplessly transformed: becoming part of a qualitatively distinct unitary mass, which guided their actions accordingly.

Weber, meanwhile, took a different tack; his emphasis on interpreting the 'actions' of 'agents' was in fact almost antithetical to Durkheim's structure (Runciman 1993: 7-42). The a priori existence and determinacy of suprapersonal entities were no longer to be taken for granted, but rather 'all events or states of affairs ... remain meaningless if no agent has consciously endowed them with meaning' (ibid.: 10). For Weber, collectives had to be constituted by the discrete social actions 
of its individuals, who elected to accord them significance or otherwise. No bonds of 'solidarity' were presumed in advance; and any abstract formation such as 'state', 'church', or 'marriage' - some of the central tenets of Durkheim's structure - were regarded as reifications, which only became relevant for the sociologist if actors considered them to be (ibid.: 30). The work of abstraction for Weber was not to understand individual behaviour through the lens of structural determinants - as Durkheim apprehended different forms of suicide - but to uncover collective logics through an interpretation of individual actions, such as his famous descriptions of various forms of 'authority' (Weber 1979). Weber's methodological individualism placed the 'actor' or 'agent' at the centre of the social universe.

It is Weber's proposition that human behaviour is irreducibly 'stochastic' (Hacking 1990) and so the 'agent' should come first, that essentially came to define organizational analysis as the twentieth century marched on. While Durkheim's structure - particularly in its later metaphysical expression (2008) found favour with subsequent generations of anthropologists, Weber's 'interpretive sociology', which he argued could only be applied to what was culturally familiar and therefore capable of comprehension (Runciman 1993: 19), shaped the latter discipline under which organizational analysis largely fell (Scott 1959; Parsons 1968).

In the 1970s and 1980s - emblematic of the postmodern taste for antinomies - two influential social theorists sought to resolve the opposition between 'agent' and 'structure' by asserting the inextricability of their union. The more well-known of these is Pierre Bourdieu and his theorization of the embodied accumulation of inherited dispositions he called the 'habitus' (1990: 54). While much of his discussion revolves around structure - which through his Marxist lens meant the 'determinate class of conditions of existence' (the social and material circumstances arising from the agent's class location) which produced the habitus (ibid.: 54), as well as the habitus itself as an ordering principle - his emphasis is wholeheartedly placed within the body of the actor. To exist, organizations had to be inhabited by individuals so inscribed. It was the habitus that enabled them to 'attain full realization' (ibid.: 57); contra Durkheim, organizations possessed no sui generis extrinsic life.

Giddens, meanwhile, was more changeoriented in emphasis, as opposed to Bourdieu's orientation towards reproduction. Like Bourdieu, Giddens' agent is one who acts in the world ('Agency refers to doing') (1984: 10); yet while 'habitus' reiterates dispositions learnt in childhood and beyond, Giddens' agent is one who decides - in his words - to 'make a difference' (ibid.: 14). Agency is thus inextricably linked to power, the causal starting point in a chain reaction which may lead to historical change. Structure, meanwhile, is a purely abstract formation: a 'virtual order' of transformative relations (ibid.: 17). It consists of rules of morality and conduct that can only be approximated by acting subjects. According to Giddens, the dualism of 'agency' and 'structure' is a fallacy, as both are part of the same duality: 'the duality of structure' (ibid.: 25). His solution, 'structuration', takes the same line as Bourdieu in its emphasis on practice, but plays upon the paradox that actors may be both enabled and constrained by the Janus-faced quality of such duality.

Finally, in the 1990s and beyond, holistic notions of constraint have appeared to evaporate entirely. Bourdieu and Giddens' focus on the indeterminacy of action, opened the doors to elaborations of 'agency' and 'creativity' which defied structural explanation (Law 1994; Rapport 2009); members of organizations were purported to inhabit a hyper-immanent world of constant happenings (Kondo 1990; Zaloom 2006). Such conceptual moves have effectively 'collapsed structure into agency' (Reed 1997: 21); thus Weber's perspective won out, while Durkheim's disintegrated into disrepute. Al- 
ways a reliable source of contemporary doxa, undergraduates are now outraged at the remorseless collective bias of the latter's orientation, appalled by his neglect of 'the individual' and their independent activity.

The current state of play can be illustrated by the comparatively long reign of 'actor-network' analysis (Law and Hassard 1999). Bruno Latour - its most vociferous advocate - drew his scholarly genealogy from Gabriel Tarde instead of Durkheim (interestingly Weber was also influenced by Tarde), and pronounced the death of 'the social' as Durkheim understood it (Latour 2005). In Latour's materialist view, the social only becomes real if actively traced, and so the work of the social analyst should be 'a sociology of associations' (ibid.: 160) - one which ignores abstractions and focuses instead on the way 'actors' forge and interact with 'networks'. He thus applied this methodology to the organizations he has examined (Latour and Woolgar 1979; Latour 2010). Latour's most radical proposition was that there are effectively no value-laden milieu which prefigure the ways these 'actor-networks' emerge: in his words 'we have to try to keep the social domain completely flat' (Latour 2005: 171). Thus for Latour the 'structure-agency problem' is resolved through the total rejection of structure, and its substitution for a universally distributed agency - an approach Bruce Kapferer called 'an individualist presentism' that is characteristic of the contemporary (2010: 188).

Yet the contemporary is multiple, and we would like to explore one of its suppressed strands, which does not accept that collapsing structure into agency is an adequate theoretical solution to the structure-agency problem. Nor, however, are we seeking some retrograde return to structural approaches. We might be better off asking: what are the limits and constraints of our actions, and how meaningful and social are these actions when they arise from situations that are themselves the products of other actions? Structure and agency are not the only constitutive practices around; there are other dynamics and social facts that can speak truth to power.

Like Bashkow (2004), we find it productive to reanimate a Boasian conception of boundaries, especially those that are erected and dismantled by people inhabiting particular organizations. By shifting the focus towards boundaries, ethnographers can show how certain contexts lead to action and meaning that is not always given nor foreclosed in various institutional/bureaucratic orderings. This perspective does not necessarily amount to delimiting freedom in action, creativity or resistance, but rather illuminates the interfaces that mould the processes and histories of organizations and organizational 'selves'. The concept of boundaries is fruitful as it demarcates types of relationships, and contextualizes claims of ownership, belonging, authority, legitimacy, and accountability. By doing so, we can improve our study of organizations by recognizing the relational nature of decision-making, interaction and other aspects of organizational work and life that are operationalized both across and because of them. Likewise, exploring the effects of boundaries rather than those of 'structures' or 'agents', may generate pragmatic solutions to forms of dysfunction, ineffectiveness or malaise which can permeate organizational life.

With that in mind, let us now offer a summary of the essays that appear in this Special Issue on the Study of Organizations. To begin with, Vita Peacock's article on the directors of the Max Planck Society challenges our preconceived and ethnocentric assumptions regarding agency. Rather than locating agency within the individual and in contradistinction to some external structure, Peacock argues that the directors of the Max Planck Institutes inherit a specific cultural history, an ideology that is carried over from the philosophical idealism of Johann Fichte (among others). It is this context, and not the director's personality (nor even the office title of director) that enables Peacock to render freedom as an analytic cat- 
egory emanating from the legacy of the 'Harnack Principle': the founding and centring of Max Planck departments around one 'central figurehead'.

Caroline Gatt's article traces how activists committed to environmentalism at 'Friends of the Earth International' experience the dynamics of power inside organizations. For Gatt, these organizations are not just the mere product of persons and their networks, but rather enlivened supra-personal agentive entities. It is in this landscape of 'legitimating environments' that activists come to experience the directionality of agency when they try to carve out a political space for cultural and ecological diversity. Gatt presents several original tools and concepts for dealing with this ontology of power as it relates to a federation, or rather an ecology of vectors in a heterarchy.

Philip Kao's article offers an inside look at how care is manufactured in a long-term care facility in the American Midwest. It also showcases how corporate culture change affects an organization in unintended ways. By observing certain institutional reforms and elder-care practices, couched in terms of a nursing home abolitionist movement known as the Eden Alternative, Kao shows ethnographically how an organization centred around the business of care squares (or does not square) with the process of ageing. His article draws from concrete ethnographic examples, and investigates what the social relations that make up the long-term care facility tell us about the regimes of care, and processes that are institutionalized and made emergent.

Finally, Jane Dickson's article looks at another kind of governmental organization. The focus here is on a sustainability and housing team inside one London borough council office. Dickson explores what happens to organizational concepts and the people who deliver 'sustainability' as they become the target of funding cuts. Rather than seeing themselves as middle management waste, the sustainability team officers struggle to maintain their linkage with an expertise they feel so much a part of and responsible for. This is not a story about de-skilling, but one of 'hollowing out'. The bitter irony of working oneself out of a job has not escaped Dickson's informants. Ultimately, the void that has to be filled by the private sector on behalf of the Big Society is a set of practices that are less creative, less flexible, less adaptable, and ultimately unsustainable.

The authors in this issue are developing intellectual tools for studying and mapping out organizations that transcend conventional models. The organizations, and the interactions of their informants within these organizations, are not neatly prescribed in pre-determined relationships (e.g. employer/ employee, contractor/client, etc.), bound by institutional rules or behavioural patterns. Neither do individual human beings have a liberal monopoly over agency; organizations can exhibit structural agency with their own histories and 'cultures'. Instead, the ethnographic accounts in these articles share an underlying concern with uncertainty. Whether it is the limitless freedom associated with the Max Planck department director (which is nullified by his or her Anstoß), or the uncertainties that unfold when Gatt's 'supra-personal entities' change positions and behaviours, people have to find ways for getting on and creating frontiers which alter the contours of yesterday's structure-agency. Paradoxically, it is the very existence of boundaries that creates the space for new forms of uncertainty.

In short, rather than focus on whether or not boundaries act as an organizational constraint, or if they can or should be transcended or broken down, a useful way forward is to investigate the dynamic nature of boundaries arising from historical and social contexts. Some organizations endure because they allow for change to occur at the interface where individuals meet at specific epistemic points of contact. Moreover, interfaces typically arise within an organization's very own structure. Individuals inhabit these boundaries, not be- 
cause they are looking to transcend the organization per se, but rather because organizations open up niches where emerging practices and ideologies require boundaries to be stretched, pushed and reproduced in new ways. Boundary stretching not only allows organizations to persist, but also allows individuals to take organizational practices into new operating contexts. With this in mind, let us now turn to the articles.

\section{Notes}

1. We are summarizing this problem only as it has intersected with the social analysis of organizations.

\section{References}

Bashkow, I. (2004). 'A Neo-Boasian Conception of Cultural Boundaries', American Anthropologist 106: 443-58, doi: 10.1525/aa.2004.106.3.443

Bourdieu, P. (1990), The Logic of Practice (Cambridge: Polity).

Durkheim, É. (1952), Suicide: A Study in Sociology (London: Routledge).

Durkheim, É. (1982), The Rules of Sociological Method (New York: The Free Press).

Durkheim, É. (1997), The Division of Labour in Society, (trans.) W. D. Halls (New York: Free Press).

Durkheim, É. (2008), The Elementary Forms of Religious Life (Oxford: Oxford University Press).

Giddens, A. (1984), The Constitution of Society: Outline of the Theory of Structuration (Cambridge: Polity).

Hacking, I. (1990), The Taming of Chance (Cambridge: Cambridge University Press).
Kapferer, B. (2010), 'Louis Dumont and a Holist Anthropology', in Experiments in Holism: Theory and Practice in Contemporary Anthropology, (ed.) Nils Bubandt and Ton Otto (Chichester: WileyBlackwell), 187-208.

Kondo, D. K. (1990), Crafting Selves: Power, Gender, and Discourses of Identity in a Japanese Workplace (Chicago: University of Chicago Press).

Latour, B. (2005), Reassembling the Social: An Introduction to Actor-Network-Theory (Oxford: Oxford University Press).

Latour, B. (2010), The Making of Law: An Ethnography of the Conseil d'Etat (Cambridge: Polity).

Latour, B. and S. Woolgar (1979), Laboratory Life: The Social Construction of Scientific Facts (Beverly Hills and London: Sage Publications).

Law, J. (1994), Organizing Modernity (Oxford: Blackwell).

Law, J. and J. Hassard (eds.) (1999), Actor Network Theory and After (Oxford: Blackwell/Sociological Review).

Parsons, T. (1968), The Structure of Social Action (New York: Free Press).

Rapport, N. (2009), Of Orderlies and Men: Hospital Porters Achieving Wellness at Work (Durham, NC: Carolina Academic Press).

Reed, M. I. (1997), 'In Praise of Duality and Dualism: Rethinking Agency and Structure in Organizational Analysis', Organization Studies 18: 21-42. doi: 10.1177/017084069701800103

Runciman, W. G. (ed.) (1993), Max Weber: Selections in Translation (Cambridge: Cambridge University Press).

Scott, F. G. (1959), 'Action Theory and Research in Social Organization', American Journal of Sociology 64: 386-95.

Weber, M. (1979), Economy and Society: An Outline of Interpretive Sociology (Berkeley and London: University of California Press).

Zaloom, C. (2006), Out of the Pits: Traders and Technology from Chicago to London (Chicago: University of Chicago Press). 